\title{
Narrow Identities Revisited
}

\author{
PARTHA DASGUPTA
}

University of Cambridge and St John's College, Cambridge

SANJEEV GOYAL

University of Cambridge and Christ's College, Cambridge

We are most grateful to the editors for inviting a discussion round our paper, Dasgupta and Goyal (2019; henceforth DG), and to Professors Carvalho, Davis, Finke, and Teschl for their most enquiring and incisive comments. They have made us look afresh at how the approach we took in our work on social identity fits into what is a substantial literature on the subject.

\section{MODELLING SOCIAL IDENTITY}

In DG, we constructed a minimalist model to explore the concept of social identity, because one's 'identity'-be it personal or social-is overly close to home; so close, that we are all tempted to make of it what we want to see in ourselves. Too much structure runs the risk of tilting the analysis toward our predispositions.

There is an obvious sense in which we all have multiple identities, spanning across our professional, social, and personal lives. That unquestionable fact has led influential commentators to view narrow social identities as a blight, founded on delusions (Sen 2006). Carvalho, in his comments on our paper, goes further and claims that "narrow identification is the exception, not the rule. It is not a natural state from which we must plot an escape route, but rather an extreme and unnatural one from which we must wonder how we got there" (79).

The thought is beguiling, but the evidence points in a different direction from what Carvalho thinks it does. The contours of our emotions were etched in the palaeolithic era. In times long ago, social groups were tiny, perhaps twenty members in a band and twenty-five bands in a tribe. We humans evolved as small group animals. If multiple identities were the norm, people would have identified themselves with 
members of all tribes they ever encountered. Evidence from archaeological and genetic records of intertribal warfare over scarce resources tell us that they didn't (see, for example, Henrich 2015, for an account of the violence that frequently characterised encounters between tribes). That is why, in their study of the diversity of human natures, evolutionary biologists have examined why we are even today disposed toward narrow identities, why when called upon, we take sides. They have explained why our social horizons are often restricted even when we have recognized that the benefits of collective enterprises could be most effectively realized if we admitted others into our group (Ehrlich 2000). In our paper, we constructed a model of personal incentives and group interests to offer an explanation that complements the one provided by evolutionary biologists.

The dilemma people face in having to choose sides is exemplified in an early book in the Iliad, where Agamemnon raises the question before the Greek armies whether they should sail home. They had been there for nine years, and Troy still stood intact. Of course, he raises the question knowing what the answer would be, and it is Odysseus who supplies it: the Greeks and their allies had made a commitment, and to leave then would be to break it. Homer tells us that the Greeks saw themselves as Greeks (the poet says they called themselves Achaeans) and were joined by, among other bonds, marriage alliances. But they and their allies would appear to have been a loose coalition, otherwise it would be hard to understand Achilles' wrath in the opening book, and his bitter complaint that he had brought his army to fight a people who had done him no wrong. Achilles' re-entry into the coalition had to do with seeking vengeance for Patroclus' death at the hands of Hector, a very personal loss. The tragedy that followed was inevitable once the Achaeans stood firm on the commitment made nine years previously. The analysis in our paper was not constructed to identify contingencies where people's loyalties would be tested, it was designed to uncover reasons people form loyalties in the first place. Contingencies oblige us to take sides, and even when the occasions are resolved peacefully, we know which side we would be on when the next push comes to shove. Carvalho's moving description of his family's experience speaks to that.

An insistence that we all have multiple identities can be read as no more than that we are all humans. The point is of course that peaceful co-existence among groups doesn't mean people parade multiple identities, it only points to accommodation having been reached. 
Showing tolerance toward others' beliefs is different from showing respect for them, for it may be that you judge their beliefs to be false and their customs so at odds with your own that you don't want to have anything to do with them socially, least of all engage in interminable 'conversations' with them. A recent publication from the Pew Research Center (Sahgal et al. 2021), based on interviews in seventeen languages with 30,000 adults from the various faiths in India, has reported that an overwhelming majority declared themselves to be deeply religious, but regardless of their religion, expressed their allegiance to religious tolerance and peaceful co-existence even while insisting on religious exclusivity and social segregation. Hindus especially declared their national identity, religion, and language to be closely connected. The model in our paper studied how exclusivity can arise even when we are not born into it.

Teschl opens her remarks by noting that "there is a difference between reasons for group or identity choice and reasoning about those reasons, which is a liberal and, so far, primarily normative concern" (107). She is right in drawing the distinction, but in our paper, we were not advocating narrow identities; rather, we were locating reasons for the prevalence of narrow identities. The 'is-ought' distinction is all important here. Teschl also suggests that the liberal cosmopolitan perspective is built on the fact that we have multiple attachments and affiliations, to which we give different priorities, and she invokes Sen (2006) in support of her view. But the fact that the multiple attachments and affiliations we have may be different from the ones we were born with, on its own proves nothing. People reasonably want to recognise the benefits and costs involved-including psychological transaction costs-before attaching priorities to them. Our model was designed to show that. We wanted to examine circumstances under which adopting a narrow identity may be in the interest of those involved. To do that, we constructed a model that showed that individuals and groups may find it in their interest to adopt a narrow notion of identity even when they have multiple attachments and are clear sighted.

Liberal cosmopolitanism is a natural position to adopt when you have the facilities to travel back and forth, and those around you are like minded (for example, in holding liberal cosmopolitan thoughts) no matter where you happen to be; it is altogether harder when you don't have that luxury. Perhaps the warm glow that accompanies liberal cosmopolitanism is inevitable when its advocacy is read by like-minded 
liberal cosmopolitans. Explanatory models, such as ours in DG, force us to imagine what it could be like to be others far removed in social space from us; and, given the constraints they face, what their concerns could be. Rootedness cannot be airily dismissed, for it serves as an anchor. That alone tells us that liberal cosmopolitanism isn't the only emergent world view, and why it is a good idea to not introduce morality in every social science exercise. Social thinkers are inevitably among society's intellectual elite, and that may be a reason they so often slide from analysis to advocacy. In our paper, we consciously avoided doing that.

\section{CONCEPTUAL Distinctions}

Davis draws attention to a literature in social psychology that distinguishes notions of 'role-based' or 'relational' social identity from 'category-based' or 'categorical' social identity (88). He suggests that in that literature category-based identity affords little room for individual autonomy or agency, whereas role-based identity comes with expectations and norms of behaviour and allows for agency. Because he thinks our model does not consider 'relational social identities', he provides as an example of such an identity someone who identifies himself as an employer. In contrast, someone who identifies herself with others would display a 'categorical social identity'. In our model, the former is a sense of the self, influencing, for example, the benefits the employer would enjoy from joining an employers' association. Joining such an association would in our model be seen as assuming a particular social identity. Of course, becoming an employer is itself an outcome of past choices and circumstances, so even the sense of the self has a history (see section III below). For an employer, the cost of joining, say, a teachers' association would typically be huge, and usually that option would not even be open to the person. Ultimately, it matters little that we did not include relational social identities explicitly in the category of social identities, because relational and categorial social identities enter the model through different routes. In any case, our intention was not to provide a classification of the various ways social identity has been identified, it was a lot more modest. We wanted to show that individuals and groups may find it in their interest to adopt a narrow notion of identity.

The distinctions between various notions of identity and their relationship with individual agency is mostly a matter of terminology. Akerlof and Kranton (2000), for example, proposed a notion of identity 
in which individuals belong to categories which come with associated norms of behaviour. As Davis remarks, certain notions of identity come with limitations on individual agency, and category-based identity would be an instance of that (91). That is one reason we constructed a model that uncovers the incentives groups have in restricting autonomy and insisting on exclusive identity. Individuals in our model, however, do have choice over whether to assume the exclusive identity demanded of them. In equilibrium, they choose to do so.

Finke asks why 'narrow' should be contrasted with 'multiple' and suggests that in our model 'narrow' might be better contrasted with 'broad'. Similarly, he wonders if it would have been better had we used the terms 'inclusive' and 'exclusive', or alternatively 'single' and 'multiple' (100). While all this is a matter of terminology, Finke is right to suggest alternative nomenclatures. Indeed, in section 6 of our paper, we present a variation on our model in which we discuss the notions of inclusive and exclusive identity.

Finke rightly says that size is not necessarily an advantage, that people are known to identify with small, exclusive groups (100). Our model was designed to specify a set of conditions that are sufficient for the emergence of narrow identities. To explore conditions that are necessary would have taken us in a different direction.

\section{TIMELESS VS DYNAMIC MODELS}

Finke believes our model has analytical flaws. He says it regards group boundaries to be immutable, whereas in practice they are fluid and evolve over time. He cites the examples of the Uzbeks, the Kachin in Myanmar, and the Vezo in Madagascar as illustrations of groups that extended their scope by including other ethnicities (102). By contrast, he says there are groups that retain a strict and narrow definition of membership.

Our model is timeless. But even within that restriction, it is possible to accommodate the inclusion of new ethnic groups. It could be that circumstances change, so that it benefits existing members of an ethnic group to accept another group to join them. If it is in the interest of the other group to join, the combined group would be larger. In any event, years of theoretical work on evolutionary biology (see, for example, Nowak 2006) have uncovered that timeless models, beloved of economists, contain in them signatures of past experiences in a society. Parameters of a timeless model hide in them the history of past choices 
and events. Irreversibility of certain classes of decisions leave an imprint because they shape the trajectory of a society's past. What is endogenous in a model with history is reduced to exogenous parameters in its timeless variant. The parameters could, for example, represent heterogeneity of people as regard their abilities, tastes, and histories. Thus, Davis argues that heterogeneity and the power relations surrounding it are central to understanding the emergence of identity in a society $(95,97)$. We agree, but our timeless model, as with all timeless models, has the past frozen in it. It would have served no purpose in our exercise to postulate heterogeneity among members of society. We would still have reached our conclusions: that the advantages size may confer on groups and the negative externalities that may prevail across groups, taken together, are a reason people could choose to assume narrow identities, or, in our model, join one side rather than another. Equilibrium in models of the sort we constructed is not necessarily unique, but we know from models of evolutionary dynamics that history matters, that even chance events in the past could have pointed toward the equilibrium that the process eventually selected. One can, of course, unpick the parameters in a timeless model and ask how they have come to be what they are in a society, such as the personal cost of harbouring multiple identities. But that would be to elaborate, not to add.

Carvalho's formulation of distance (see equation (1) in his comment, 81) and his definition of narrow and broad identity is useful. The issue of dormant allegiances is natural in our context. There is also the issue of contingencies that interact with these dormant identities. The two often go together and will be important in practice. A possibility is to study steady states or stable configurations in a dynamic setting to illuminate these relations. The stability notions could be defined in such a way as to incorporate the 'within' and 'across' group mechanisms he elaborates (82-84). Such a model would help us understand the vector of weights on identity dimensions that are stable, as a function of different parameters of initial 'dormant' identity configurations and the character of social interactions, which would be endogenous.

Davis is entirely right that we left no space to discuss the connections between 'personal' and 'social' identities, and suggests the connections are hard to conceptualise (91). It is a gift of the concept of equilibrium that it severs the distinction between cause and effect. Our sense of the self plays a role in our ability and the choices we make regarding which social group(s) to join, but social interactions with 
others in the group(s) we join in turn influence our sense of the self. In a model that works through time, such mutual influences would be sequential, subject of course to uncertain contingencies; but in equilibrium, should the social system converge to an equilibrium, the mutual influences would be in balance. They would be solutions of a system of equations representing (stochastic) equilibrium conditions.

In a complex system, and a human society may be so regarded, it may be that there is no equilibrium to which it converges. It may even be that the system is chaotic, but if that were so, little could be said regarding the evolution of personal and social identities. Historical evidence, however, does not point to chaotic time series in such significant economic variables as the share of profits in national income, let alone in national income itself. So, our timeless model probably does not mislead. In any case, there are complex systems that display chaotic behaviour among small subsystems but regular behaviour in the aggregate (unpredictability of the weather in contrast to regularity of climate is an example). We are thus at one with Finke, where he writes, "ethnic groups may lead long lives in spite of a constant flow of people across their boundaries" (101).

\section{THEORY AND FIELDWORK}

Finke is nearly right when he says that "economists develop models rather than doing fieldwork to observe what people actually do and how they interrelate" (101). But only nearly. Fieldwork among communities, conducted by ecological economists in recent years (see, for example, Ghate, Jodha, and Mukhopadhyay 2008), has started unravelling intricate sets of social norms of behaviour in these communities. Such behavioural norms provide incentives to community members to manage their local resource base sustainably in circumstances where the rule of law, as conventionally understood, is not near at hand. Norms are known to differ across ecological niches, the task that theoretical economists have undertaken has been to interpret those differences in terms of differences in the character of the niches (Dasgupta 2021). Communitarian management of coastal fisheries in the tropics requires a different set of rules from what they would be in temperate zones, and both would be expected to differ from those in place in grazing lands or tropical rainforests. More generally, economic theorists use data collected by scholars conducting fieldwork to make sense of them, at least when seen through the lens of economics. 


\section{REFERENCES}

Akerlof, George A., and Rachel E. Kranton. 2000. "Economics and Identity." The Quarterly Journal of Economics 115 (3): 715-753.

Dasgupta, Partha. 2021. The Economics of Biodiversity: The Dasgupta Review. London: HM Treasury.

Dasgupta, Partha, and Sanjeev Goyal. 2019. "Narrow Identities.” Journal of Institutional and Theoretical Economics 175 (3): 395-419.

Ehrlich, Paul R. 2000. Human Natures: Genes, Cultures, and the Human Prospect. Washington, DC: Island Press.

Ghate, Rucha, Narpat Jodha, and Pranab Mukhopadhyay. 2008. Promise, Trust, and Evolution: Managing the Commons of South Asia. Oxford: Oxford University Press.

Henrich, Joseph P. 2015. The Secret of Our Success: How Culture Is Driving Human Evolution, Domesticating Our Species, and Making Us Smarter. Princeton, NJ: Princeton University Press.

Nowak, Martin A. 2006. Evolutionary Dynamics: Exploring the Equations of Life. Cambridge, MA: The Belknap Press of Harvard University Press.

Sahgal, Neha, Jonathan Evans, Ariana Monique Salazar, Kelsey Jo Starr, and Manolo Corichi. 2021. "Religion in India: Tolerance and Segregation." Pew Research Center, June 29, 2021. https://www.pewforum.org/2021/06/29/religion-in-indiatolerance-and-segregation/.

Sen, Amartya K. 2006. Identity and Violence: The Illusion of Destiny. New York, NY: W. W. Norton.

Partha Dasgupta, FBA, FRS, is the Frank Ramsey Professor Emeritus of Economics, University of Cambridge and Fellow of St John's College, Cambridge. His publications include Human Well-Being and the Natural Environment (2nd ed., 2004), Economics: A Very Short Introduction (2007), and his Kenneth Arrow Lectures, Time and the Generations: Population Ethics for a Diminishing Planet (2019).

Contact e-mail: <pd10000@cam.ac.uk>

Sanjeev Goyal, FBA, is Professor of Economics, University of Cambridge and Fellow of Christ's College, Cambridge. He published Connections: An Introduction to the Economics of Networks in 2007; a new book, Principles of Networks, is to be published in 2022.

Contact e-mail: <sg472@cam.ac.uk> 